Brit. J. industr. Med., 1949, 6, 221.

\title{
VITAL CAPACITY MEASUREMENTS IN CORNISH TIN-MINERS
}

\author{
BY \\ JESSIE GARRAD \\ From the Department for Research in Industrial Medicine (Medical \\ Research Council), London Hospital
}

(RECEIVED FOR PUBl.ICATION MAY 19, 1949)

\section{Introduction}

The first measurements of vital capacity were made by Hutchinson in 1846. During the 1914-18 war there was renewed interest in vital capacity measurement both in England and America following the suggestion that it might be used as an index of physical fitness. In an effort to find a method of calculating the normal figure for any individual, attempts were made on both sides of the Atlantic to relate the observed vital capacity of normal healthy males to some physical measurement, such as height, weight, surface area, stem height, or chest expansion.

The results of these investigations have been well summarized by Hewlett and Jackson (1922). These workers also calculated the correlation coefficients for vital capacity with height, height and weight, surface area (from du Bois' Tables) in a group of 400 male students aged 18 to 30 years. Lemon and Moersch (1924) compared the classifications and formulæ for determining the normal vital capacity proposed by Hutchinson (1846), Schuster (1911), Peabody and Wentworth (1917), Lundsgaard and van Slyke (1918), Dreyer (1919), West (1920), Hewlett and Jackson (1922), and Myers (1923). They concluded that West's formula was the most exact and the easiest to use. West stated that the vital capacity of males was 2.5 litres per sq. metre of surface area.

During the decade prior to the 1939-45 war there was a tendency not to relate the vital capacity to the physical measurements previously used, but to consider the lung volume subdivisions in relation to each other and to the total lung volume. At the same time these volumes were related to a new measurement, the so-called "radiological chest volume," a concept first introduced by Lundsgaard and van Slyke (1918) and developed by Hurtado and Fray (1933a) and Aslett, Hart, and McMichael (1939). This " radiological chest volume" is the theoretical thoracic volume. It consists in principle of the aren of the lung fields and heart shadow (obtained by measurement of a chest film) multiplied by the antero-posterior diameter of the chest at full inspiration.

Hurtado and Fray, working on 50 healthy male medical students of 18 to 30 years, found a correlation between radiological chest volume antd vital capacity of $+0 \cdot 7174 \pm 0 \cdot 0467$. The regression equation relating these variables was

vital capacity $=(0.24 \times$ rad. chest vol. in litres $)+$ $1 \cdot 22$ litres

Aslett, Hart, and McMichael determined the relation of the lung volume and its subdivisions to various physical and radiological measurements in 64 South Wales coal-miners of 19 to 63 years with normal chest radiographs. They found that the correlation coefficient for radiological chest volume and vital capacity was +0.63 , and the regression equation was

vital capacity $=(0.0031 \mathrm{x}$ rad. chest. vol. in c. ins. $)+$ 1.25 litres

As these authors point out, while Hurtado's films were taken at a distance of $6 \mathrm{ft}$., theirs were taken at $4 \frac{1}{2} \mathrm{ft}$., which would give an increase in the area of the lung fields of approximately 4 per cent. over those of Hurtado. Also their measurements were made with the subject in a sitting posture while Hurtado's students were recumbent. This position would reduce the total lung volume by 9 or 10 per cent., the vital capacity by slightly less, and the radiological chest volume by 8 per cent. as compared with the sitting subjects (Hurtado and Fray, 1933b).

Parallel with these developments were attempts to estimate the normal reduction in the vital capacity with increasing age. Myers and Cady (1924) reviewed the literature and from their own observations clearly established this reduction. Kaltreider, Fray, and Hyde (1938) also summarized the results of previous work and estimated the changes with age in the lung volume and its subdivisions of a series of 
normal males between 38 and 63 years. They found that in men of the fifth and sixth decades there were marked variations in the absolute values of the total lung volume and its subdivisions, but that the vital capacity might still be predicted with " a reasonable degree of accuracy" from the radiological chest volume. They concluded that the vital capacity decreases progressively from the third to the eighth decade, but a deviation of the observed volume of less than 20 per cent. from the calculated volume could be considered as within normal limits. A deviation of more than 20 per cent. would be due to other factors than age.

These authors and their co-workers also studied the relation of the observed lung volume and its sub-divisions to the corresponding volumes calculated from the radiological chest volume in 58 cases of pulmonary fibrosis. These were 57 men and one woman who, except for 4 , had been exposed to inorganic industrial dusts from one to 40 years. Their ages ranged from 31 to 71 years (Hurtado and others, 1935). In a further paper Kaltreider, Fray, and Hyde (1937) correlated the observed measurements on the 58 cases already reported with the calculated volumes corrected for age as previously described (Kaltreider, Fray, and Hyde, 1938), and 32 new cases were added. The observations of these 90 cases were correlated with $x$-ray changes. The cases were divided into six groups depending on the degree of pulmonary fibrosis. Ignoring the two groups where the fibrosis was complicated by emphysema, a decrease in the mean observed vital capacity for each group, expressed as a percentage of the mean calculated volume for that group, was obtained with increasing degree of fibrosis.

\section{Present Investigation}

During the course of an investigation into pneumoconiosis among Cornish tin-miners conducted by the Department for Research in Industrial Medicine, measurements of vital capacity were made on the men examined clinically and radiologically at Geevor and South Crofty mines. The object was to determine the association between vital capacity and radiological lung changes and to assess the value of the vital capacity measurement as an index of a man's pulmonary condition during a survey lasting several years.

INITIAL SURVEY : MARCH 1946

Methods.-A "British Benedict" basal metabolism apparatus was used with a recording drum operated by clockwork. The subject sat in an upright chair, in such a position that he could not see the recording drum. Each tracing lasted approximately four minutes. A recording of tidal air was made for the first $1 \frac{1}{2}$ to 2 minutes or until a steady base line was established, then one recording each of complemental air, reserve air, and vital capacity was taken with about $\frac{1}{2}$ minute of tidal breathing after each. Various physical measurements were made on the majority of men examined clinically : weight (in singlet and trousers) to the nearest pound, standing height (in socks) to the nearest half inch, stem height and chest expansion both to the nearest quarter inch.

A detailed occupational history was taken from each man, from which could be calculated the length of exposure to dusts in metalliferous mining, and also the total exposure to silica-containing dusts incurred in a variety of additional occupations such as coal-mining, foundry work, and granite masonry. The man's age was also recorded.

The radiographs were taken with the Mobile Unit of the Joint Council of the British Red Cross Society and Order of St. John. The Mobile Unit is self-contained, with low tension generator of special design, having an output of 525 volts at a frequency of 100 cycles. Thermostatic control of the processing unit is provided in addition to air conditioning for interior working. Complete range of accessories is also housed in special fittings and containers. The $x$-ray unit is also of special design, 4-valve type with comprehensive control panel and accurate valve timer, reading $0.04-8$ seconds. The technique used on the investigation was as follows :

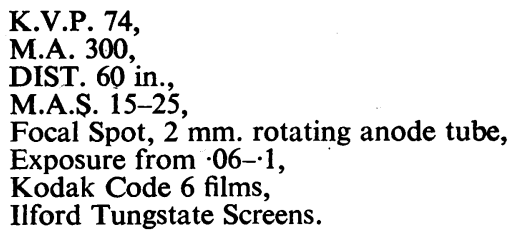

Precise engine governing is incorporated in the 27-h.p. engine driving the alternator, maintaining the engine and frequency at constant speed, plus an efficient voltage regulation which provided for accurate control throughout the entire investigation.

Each chest radiograph was classified into one of four groups, I to IV, depending on the severity of lung changes, although for the following statistical analysis it was often necessary to combine groups II, III, and IV, owing to smallness of numbers. The films were classified as follows :

Group I : within the limits of normal.

Group II : excessive diffuse shadowing which might be described as doubtful reticulation.

Group III : reticulation.

Group IV : nodulation and/or massive shadows.

Complete data consisting of vital capacity, age, $x$-ray group, length of exposure in metalliferous mining and to siliceous dusts, were obtained for 134 men at Geevor; a further 7 men were partially examined; approximately 20 men refused to cooperate at all. At South Crofty, the above data was obtained for 128 men; four men were partially 
examined; again about 20 men refused to cooperate. Therefore a total of 262 complete observations was available for analysis.

Results.-The comparison of the mean and standard deviation of the vital capacity of workers at the two mines showed that for Group I (normal) and also for groups II, III, and IV combined (abnormal), the difference between the two mines was not significant (Table 1). The analysis of variance gives :

\begin{tabular}{|c|c|c|}
\hline & Variance & \\
\hline & $1 \cdot 89$ & $0.2>P>0.05$ \\
\hline $\begin{array}{l}\text { bnormal } x \text {-ray group (II, } \\
\text { III, IV) } \ldots \\
\text { Ill } x \text {-ray groups } \ldots\end{array}$ & $\begin{array}{l}0.51 \\
1 \cdot 78\end{array}$ & 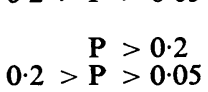 \\
\hline
\end{tabular}

In each mine the mean vital capacity of the abnormal group was smaller than that of the normal group, and at Geevor this difference was significant.

\begin{tabular}{|c|c|c|}
\hline & $\begin{array}{l}\text { Variance } \\
\text { ratio }\end{array}$ & $P$ \\
\hline $\begin{array}{l}\text { Geevor } \\
\text { South Crofty } \ldots \\
\text { Both mines combined }\end{array}$ & $\begin{array}{r}14 \cdot 63 \\
3 \cdot 15 \\
15 \cdot 73\end{array}$ & $0.2>\begin{array}{l}\mathrm{P}<0.001 \\
\mathrm{P}>0.05 \\
\mathrm{P}<0.001\end{array}$ \\
\hline
\end{tabular}

However, vital capacity is negatively correlated with age. From the 262 observations of these Cornish data a significant correlation coefficient (r) between the two variables age and vital capacity was obtained : $\mathrm{r}=-0.453, \mathrm{t}=8.19$, and $\mathrm{P}<0.001$. A

TABLE 1

VITAL CAPACITY OF MINERS BY $x$-RAY CATEGORY AND MINE

\begin{tabular}{|c|c|c|c|}
\hline & \multicolumn{3}{|c|}{$X$-ray group } \\
\hline & Normal & $\begin{array}{c}\text { Abnor- } \\
\text { mal }\end{array}$ & Total \\
\hline $\begin{array}{l}\text { GEEVOR } \\
\text { No. of observations .. }\end{array}$ & 101 & 33 & 134 \\
\hline $\begin{array}{ccc}\text { Mean vital } & \text { capacity } \\
\text { in } \mathrm{c.cm} . & \ldots & .\end{array}$ & 3441 & 2859 & 3298 \\
\hline S.D. in c.cm. .. $\quad \ldots$ & 786 & 668 & 797 \\
\hline $\begin{array}{l}\text { SOUTH CROFTY } \\
\text { No. of observations }\end{array}$ & 75 & 53 & 128 \\
\hline $\begin{array}{c}\text { Mean vital capacity } \\
\text { in c.cm. }\end{array}$ & 3275 & 2996 & 3159 \\
\hline S.D. in c.cm. .. & 804 & 964 & 881 \\
\hline $\begin{array}{l}\text { TOTAL } \\
\text { No. of observations .. }\end{array}$ & 176 & 86 & 262 \\
\hline \begin{tabular}{ccc} 
Mean vital & \multicolumn{2}{c}{ capacity } \\
in c.çm. & $\ldots$ &.
\end{tabular} & 3370 & 2944 & 3230 \\
\hline S.D. in c.cm. .. & 796 & 861 & 840 \\
\hline
\end{tabular}

convariance analysis was therefore carried out to correct vital capacity for age differences between the normal and abnormal $x$-ray groups. As a result the reduction in the mean vital capacity of the abnormal compared with the normal group was no longer obtained. In other words the abnormal group consisted of older men, and the age factor masked any influence that the lung condition, as seen radiologically, might have exerted on the vital capacity.

But this method revealed differences between the two mines, regardless of $x$-ray classification. A significant reduction in the mean vital capacity of all South Crofty men compared with all Geevor miners was obtained : also the mean vital capacity for all normal men was significantly less at South Crofty than at Geevor. This is shown by the variance ratios.

\begin{tabular}{|c|c|c|}
\hline , & $\begin{array}{l}\text { Variance } \\
\text { ratio }\end{array}$ & $\boldsymbol{P}$ \\
\hline $\begin{array}{l}\text { Normal } x \text {-ray group } \\
\text { Abnormal } x \text {-ray group }\end{array}$ & $\begin{array}{l}4.78 \\
0.36\end{array}$ & $\begin{aligned} 0.05> & P \\
P & >0.01 \\
P & >0.2\end{aligned}$ \\
\hline All $x$-ray groups & $4 \cdot 66$ & $0.05>P>0.01$ \\
\hline
\end{tabular}

When all 262 observations were considered, a regression coefficient of $\mathbf{3 2 . 7 9}$ was obtained between vital capacity and age, and for vital capacity and length of exposure in metalliferous mining the regression coefficient was $\mathbf{0 . 8 5}$. The former was statistically significant (standard error $=5.94, t=5.53$ and $\mathrm{P}<0.001$ ) while the latter was not (standard error $=6.51, \mathrm{t}=0.13$ and $0.9>P>0.8)$. Therefore there is no advantage in estimating an "expected" vital capacity from length of exposure as well as from age, since the improvement to be obtained would be negligible.

In view of the significant difference between the mean vital capacity corrected for age of normal men at Geevor and South Crofty, it was felt that the vital capacity was associated with some other factor that differed between the two mines.

The men classified as normal, Group I, were therefore studied in more detail in an attempt to relate vital capacity to one of the many physical measurements taken. The data was complete for the 101 normal men at Geevor and for 74 of the 75 normal men at South Crofty. The description of these two populations in terms of the mean and standard deviations of the variables under consideration is summarized in Table 2.

It can be seen that at Geevor the mean figures were higher than at South Crofty for age, vital capacity, lengths of exposure to metalliferous mining and to silica dusts, and lower for height and weight, but none of these differences was statistically significant. At Geevor, however, the means for stem height and chest expansion were significantly higher than at South Crofty. 
TABLE 2

THE MEAN AND STANDARD DEVIATION OF VITAL CAPACITY, AGE, LENGTH OF EXPOSURE TO METAL MINING, LENGTH OF EXPOSURE TO SILICA DUST, STANDING HEIGHT, WEIGHT, STEM HEIGHT, AND CHEST EXPANSION OF THE MINERS AT GEEVOR AND SOUTH CROFTY

\begin{tabular}{|c|c|c|c|c|c|c|c|c|c|c|c|}
\hline \multirow{2}{*}{\multicolumn{3}{|c|}{ Variable }} & \multicolumn{2}{|c|}{ Geevor } & \multicolumn{2}{|c|}{ South Crofty } & \multicolumn{2}{|c|}{ Total } & \multicolumn{3}{|c|}{ Difference (Geevor-South Crofty) } \\
\hline & & & Mean & S.D. & Mean & S.D. & Mean & 'S.D. & $\begin{array}{l}\text { Differ- } \\
\text { ence }\end{array}$ & $\mathrm{t}$ & $\mathbf{P}$ \\
\hline \multicolumn{3}{|c|}{ Number of observations } & \multicolumn{2}{|c|}{101} & \multicolumn{2}{|c|}{74} & \multicolumn{2}{|c|}{175} & & & \\
\hline \multicolumn{3}{|c|}{ Vital capacity in c.cm. } & 3441 & 786 & 3281 & 808 & 3373 & 797 & 160 & $1 \cdot 32$ & $0.2>P>0.1$ \\
\hline Age in years. . & . & . & $33 \cdot 65$ & $10 \cdot 35^{\prime}$ & $30 \cdot 70$ & $9 \cdot 73$ & $32 \cdot 41$ & $10 \cdot 17$ & $2 \cdot 95$ & 1.91 & $0.1>P>0.05$ \\
\hline \multicolumn{3}{|c|}{$\begin{array}{c}\text { Length of exposure in metal } \\
\text { mines in years } \ldots\end{array}$} & $9 \cdot 69$ & $7 \cdot 91$ & $7 \cdot 84$ & $7 \cdot 44$ & $8 \cdot 91$ & $7 \cdot 75$ & $1 \cdot 85$ & $1 \cdot 57$ & $0.2>P>0.1$ \\
\hline \multicolumn{3}{|c|}{ Length of exposure to silica } & $12 \cdot 52$ & $8 \cdot 90$ & $10 \cdot 45$ & $8 \cdot 18$ & $11 \cdot 65$ & $9 \cdot 22$ & $2 \cdot 07$ & $1 \cdot 45$ & $0.2>P>0.1$ \\
\hline Height in inches & . & . & $66 \cdot 35$ & $2 \cdot 71$ & $66 \cdot 43$ & $2 \cdot 70$ & $66 \cdot 38$ & $2 \cdot 70$ & -0.08 & $0 \cdot 21$ & $0.9>P>0.8$ \\
\hline Weight in lb. & . & . & $144 \cdot 81$ & $19 \cdot 46$ & $145 \cdot 91$ & $20 \cdot 90$ & $145 \cdot 27$ & $20 \cdot 03$ & $-1 \cdot 10$ & $0 \cdot 36$ & $0.8>P>0.7$ \\
\hline Stem height in inc & hes & & $35 \cdot 00$ & $1 \cdot 24$ & $33 \cdot 69$ & $1 \cdot 31$ & $34 \cdot 44$ & $1 \cdot 42$ & $1 \cdot 31$ & $6 \cdot 72$ & P. $<0.001$ \\
\hline Chest expansion ir & inches. & & 3.29 & $1 \cdot 12$ & $2 \cdot 63$ & 0.73 & $3 \cdot 01$ & 1.02 & $\underline{0.66}$ & $4 \cdot 43$ & $P<0.001$ \\
\hline
\end{tabular}

Table 3 shows that the correlation between vital capacity and each of the variables age, length of exposure to silica dusts, height, and chest expansion was significant both at Geevor and at South Crofty. However, the differences between the corresponding correlations at the two mines were not significant. As these differences were not significant it was possible to pool the data and again a significant correlation was obtained between vital capacity and each of the variables.

The correlation between vital capacity and exposure in metalliferous mining was significant at Geevor but not at South Crofty; for stem height and weight the position was reversed, being insignificant at Geevor and significant at South Crofty. The correlations for vital capacity with weight were not significantly different at the two mines; the correlations for vital capacity with exposure in metalliferous mining and with stem height were significantly different at the two mines.

But none of this analysis accounts for the difference in the mean vital capacity of normal men at Geevor and South Crofty.

\section{Follow-UP SURVEY : 1947}

Methods.-When the follow-up was conducted at Geevor Mine only, in 1947, it was decided to relate the vital capacity to the radiological chest volume.

The technique for the radiological examination was the same as that in 1946 but the films were taken on a $14 \mathrm{in.}$ by 17 in. plate, instead of 12 in. by 15 in., to include the whole of the lung fields. Three plates each were taken for about one-third of the men $x$-rayed, and two plates each for another third.

The measurement of radiological chest volume was obtained from the area of the lung fields (including the heart shadow) on the $x$-ray film and from the anteroposterior diameter measured with callipers at the level of the nipple line at full inspiration. The boundaries of the lung fields as seen on the film were, for this purpose, assumed to be the line joining the inner edge of the crests of the first ribs, and laterally the line joining the inner crests of the ribs, and, at the base, the highest line of the diaphragm. This area was marked out on each radiograph with a yellow grease pencil (fig. 1) and measured with a planimeter; the mean of five measurements of each plate was used. This area multiplied by the antero-posterior diameter at full inspiration gives the radiological chest volume.

As in 1946, the radiographs were classified into groups I to IV depending on the severity of lung changes.

The same respiratory apparatus was used as in 1946 with essentially the same circuit. The resistance of the circuit was reduced by the substitution of very light valves and by using less soda lime in the chimney : the reduction in the resistance was less fatiguing for the subjects but was not sufficient to result in a significant increase in the vital capacity measurement.* In the 1947 survey each recording consisted of a seven-minute tracing with five measurements of vital capacity, each

* Repeat tracings taken six months after the original measurements in 1946, after modification of the circuit, showed for 69 men at Geevor a mean increase in the vital capacity of $71.20 \mathrm{c.cm}$. S.D. 49.51 , and for 59 men at South Crofty an increase of $120.76 \mathrm{c.cm}$. S.D. 564.85 . Both these differences are statistically insignificant. 
preceded by about one minute of tidal breathing. The temperature of the spirometer gases and the barometric pressure were noted at the end of each recording. The observed measurements of vital capacity were corrected to body temperature of $37^{\circ} \mathrm{C}$. and pressure of $45 \mathrm{~mm}$. $\mathrm{Hg}$, not $47 \mathrm{~mm} . \mathrm{Hg}$ as the air in the lungs is not fully saturated (Christie and Loomis, 1933).
The correction factor therefore is :

$$
\frac{\text { B.P. }-(\text { V.P. at } T)}{760-45}+\frac{273+37}{273+\mathrm{T}}
$$

where B.P. $=$ Barometric pressure in mm.Hg. V.P. = Vapour pressure in $\mathrm{mm}$. Hg.

T. = Observed temperature in ${ }^{\circ} \mathrm{C}$.

TABLE 3

ZERO ORDER CORRELATION COEFFICIENTS (r) AND REGRESSION COEFFICIENTS (b) BETWEEN VITAL CAPACITY AND REMAINING VARIABLES

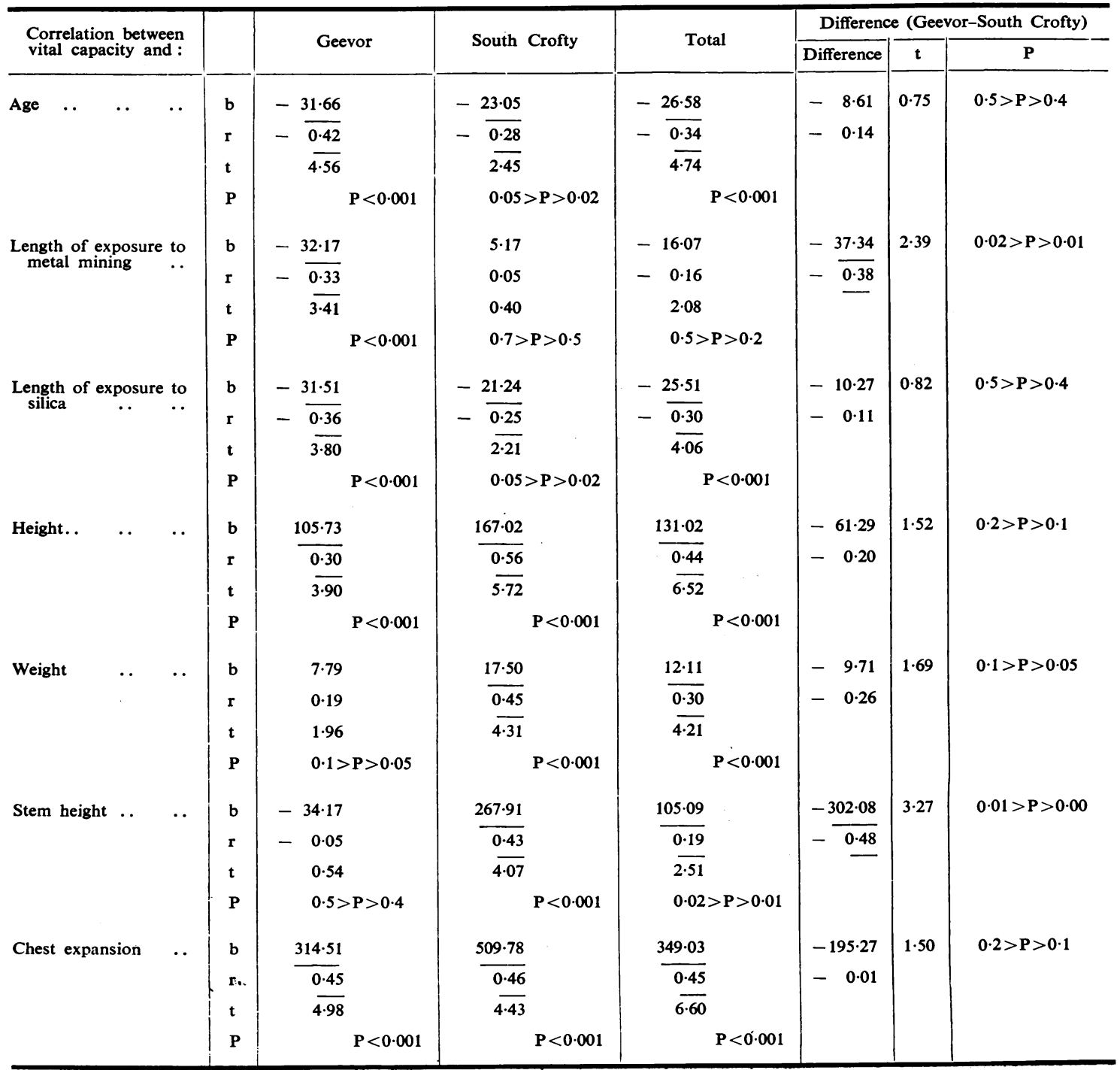


The following information was therefor obtained about each subject: age, $x$-ray group, vital capacity (mean of five measurements) corrected for temperature and pressure, and radiological chest volume (mean of five measurements of each plate). These data were used in testing whether any relationship existed between vital capacity and radiological chest volume among the normal $x$-ray group, and if a correlation existed, whether these two variables could be used to distinguish cases on the borderlines between the four $x$-ray groups, and whether a man's progress could be assessed annually by expressing his observed vital capacity as a percentage of the normal " expected " volume calculated from the radiological chest volume.

\section{Results}

Of the 134 men fully examined in 1946,48 had left by 1947 . Of the 86 remaining, 63 were fully and 11 partially examined, and 12 were absent or refused examination. In order to increase the numbers, additional men were examined for the first time, including new employees and men who had refused in 1946. Full data were therefore obtained for 105 men out of a total population of 168 . Of the remainder, 30 were partially examined, and 33 were not examined through sickness, or through refusal to cooperate. Of these 33, 14 had been fully and 4 partially examined in 1946 , leaving only 15 who had not been examined at all. Their details of age, occupation, and length of exposure at Geevor were obtained from the employers, and it is not thought that the exclusion of these men biases the results.

The inter-relation, between age, vital capacity, and radiological chest volume for 62 normal men is

TABLE 4

INTER-RELATION BETWEEN AGE, VITAL CAPACITY, AND RADIOLOGICAL CHEST VOLUME FOR 62 NORMAL MEN (GEEVOR, 1947)

\begin{tabular}{c|c|c|c}
\hline & $\mathrm{r}$ & $\mathrm{t}$ & $\mathrm{P}$ \\
\hline $\begin{array}{c}\text { Vital capacity and } \\
\text { age } . .\end{array} \quad$. & -0.46 & 4.04 & $<0.001$ \\
$\begin{array}{c}\text { Vital capacity and } \\
\text { ra diolo g i c a 1 } \\
\text { chest volume .. }\end{array}$ & 0.63 & 6.36 & $<0.001$ \\
$\begin{array}{c}\text { Radiological chest } \\
\text { volume and age }\end{array}$ & -0.07 & 0.57 & $0.6>\mathrm{P}>0.5$ \\
\hline
\end{tabular}

shown in Table 4. This shows that there was a significant and positive correlation between vital capacity and radiological chest volume of +0.63 (the same figure obtained by Aslett, Hart, and McMichael, 1939). The regression equation relating these two variables was :

vital capacity $=(4.595 \times$ rad. chest vol. in c. in. $)-$ $134 \cdot 20 \mathrm{c.cm}$.

A significant and negative correlation between vital capacity and age of -0.46 was also obtained. The radiological chest volume was unaffected by age.

When the analysis was extended to cover the four $x$-ray groups, that is, all 105 men examined in 1947 (Table 5), it was found that for radiological chest volume the variance ratio was less than 1 and therefore there was no association between radiological chest volume and $x$-ray categories. For vital capacity the variance ratio was 3.363 and $0.05>P>0.01$. Therefore the difference of vital capacity between $x$-ray groups was significant and there was a definite relationship between vital capacity and $x$-ray category. 
TABLE 5

ANALYSIS OF VARIANCE OF RADIOLOGICAL CHEST VOLUME, AND OF VITAL CAPACITY WITH $x$-RAY CATEGORIES (105 OBSERVATIONS)

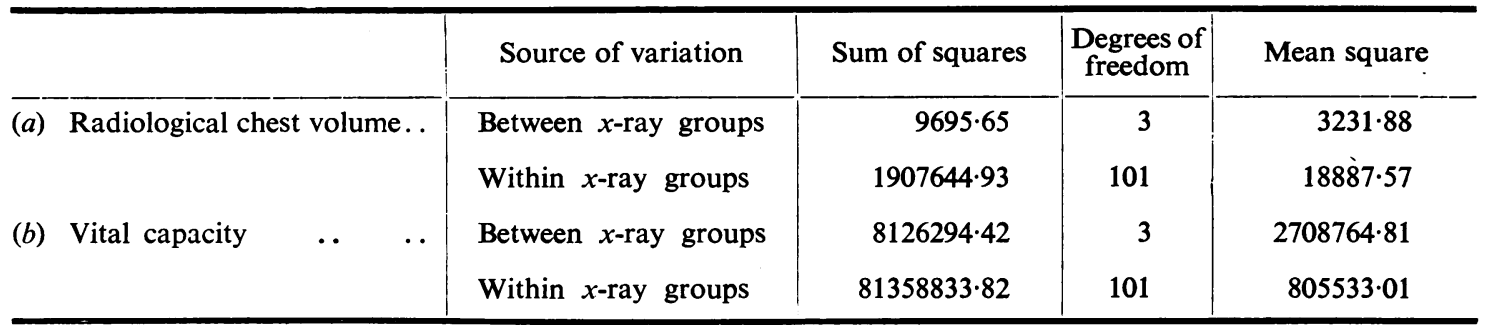

However, vital capacity is negatively correlated with age, and there was a different age composition of the four $x$-ray groups. Therefore when the effect of age on the relation between vital capacity and $x$-ray groups was determined, it was found that the variance ratio was less than unity and that therefore vital capacity was not related to $x$-ray group when allowance was made for age (Table 6). It has already been shown that there was no relation between radiological chest volume and age, nor between radiological chest volume and $x$-ray group, and consequently the radiological chest volume was not related with $x$-ray category when allowance was made for age.

An alternative method of presenting the same data is shown in Table 7. The observed mean vital capacity decreased from group I to IV, but the mean age increased; that the decrease in mean vital capacity was a function of age is shown by the fact that the observed volumes for $x$-ray groups I, II, and III approximated very closely to the "expected" volumes calculated from the regression equation between age and vital capacity for the 62 normal subjects. In group IV the observed volume was lower than one would expect, even allowing for age, but the reduction was not statistically significant.

Table 7 also shows that the mean radiological chest volume was practically the same in all four $x$-ray groups. Consequently there was little difference between the " expected" mean vital capacity for each group, calculated from the regression equation between vital capacity and radiological chest volume obtained from 105 observations. As would be expected, similar but slightly higher volumes resulted when the regression equation obtained from the 62 normal observations only was used.

When the " expected" vital capacity was calculated in terms of the radiological chest volume, the overlap between the volumes for the four $x$-ray groups can be seen from fig. 2 .

\section{Discussion and Conclusions}

The mean " expected" volumes for groups I, II, and III lie very close together, and the mean " expected" values for group IV are much lower, especially for the larger radiological chest volumes. When, however, the standard deviations of the mean values are considered, it can be seen that there is much overlapping between the " expected "volumes for each group.

Therefore when considering a subject whose $x$-ray appearance falls on the borderlines between $x$-ray groups, it is not possible to obtain assistance in classifying him by comparing his observed vital capacity with the calculated vital capacity using the regression equation between radiological chest volume and vital capacity.

Neither is it possible to trace a man's progress from year to year by relating his observed vital capacity to the " expected " vital capacity calculated in terms of radiological chest volume, as the limits

TABLE 6

ANALYSIS OF VARIANCE OF RADIOLOGICAL CHEST VOLUME AND OF VITAL CAPACITY WITH $x$-RAY CATEGORIES CORRECTED FOR AGE

\begin{tabular}{|c|c|c|}
\hline & $\begin{array}{l}\text { Source of } \\
\text { variation }\end{array}$ & $\begin{array}{c}\text { Corrected } \\
\text { mean } \\
\text { square } \\
\text { estimate }\end{array}$ \\
\hline $\begin{array}{l}\text { (a) Radiological } \\
\text { chest volume }\end{array}$ & $\begin{array}{l}\text { Between } x \text {-ray groups } \\
\text { Within } x \text {-ray groups }\end{array}$ & $\begin{array}{r}2983 \\
19058\end{array}$ \\
\hline (b) Vital capacity & $\begin{array}{l}\text { Between } x \text {-ray groups } \\
\text { Within } x \text {-ray groups }\end{array}$ & $\begin{array}{l}426506 \\
673397\end{array}$ \\
\hline
\end{tabular}

within which the calculated "expected" vital capacity would fall are so wide as to include the whole possible range of observed vital capacity measurements. For example, it can be seen from the graph that the normal "expected" vital capacity for a man with a radiological chest volume of 
900 c.in. is $4000 \pm 1300$ c.cm. So that unless his observed vital capacity decreased to less than $2700 \mathrm{c} . \mathrm{cm}$. it could not be classed as abnormal. If the observed vital capacity is expressed as a percentage of the " expected "volume without regard to the standard deviation of this volume, anomalous and misleading figures may result. For example, one man in group I had a vital capacity 64 per cent. of the "expected" volume, while another in group III was as high as 125 per cent., and one in group IV, 95 per cent.

\section{Summary}

1. Since 1846 attempts have been made to relate the vital capacity of normal males to some physical or radiological measurement in order to calculate the "expected"

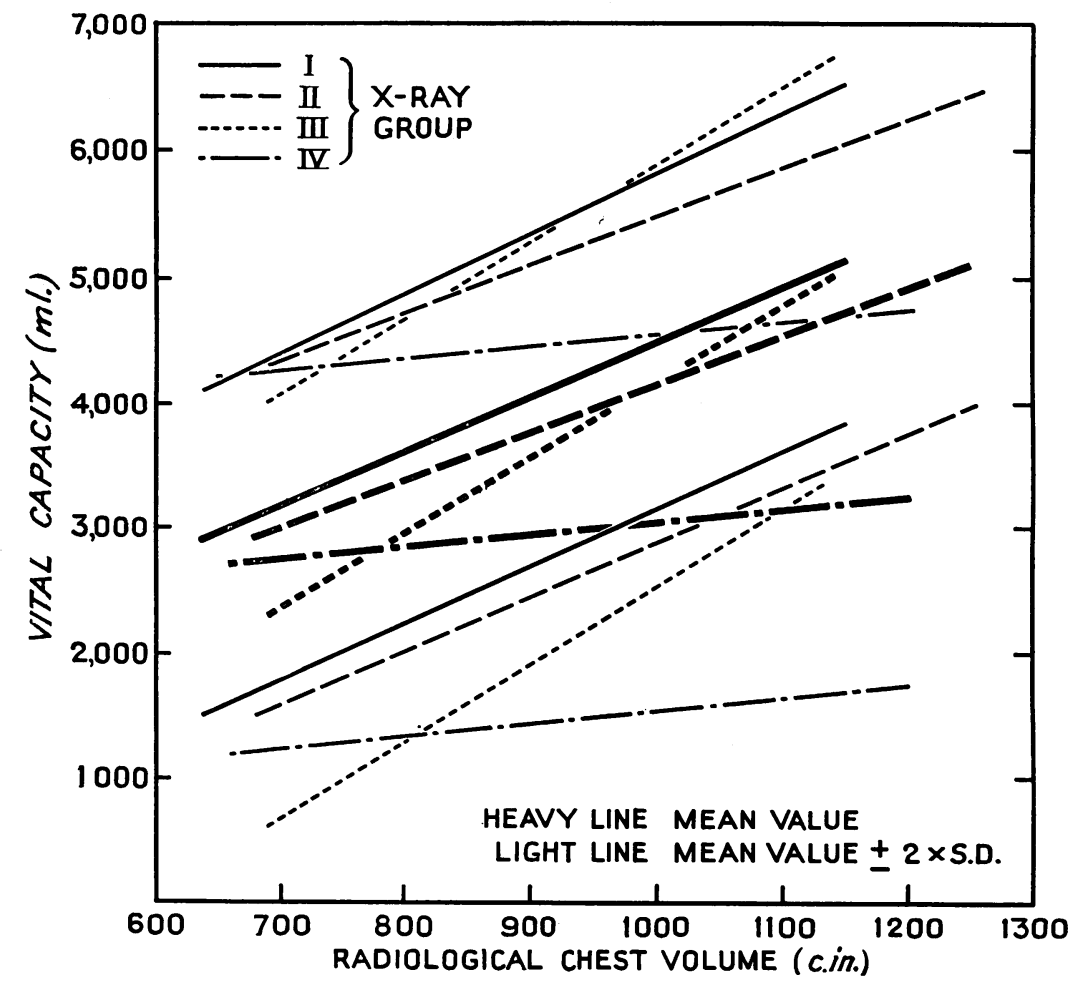

FIG. 2.-Graph illustrating relation between vital capacity and radiological chest volume for each $x$-ray group.

vital capacity for any given individual. The examined clinically and radiologically at Geevor and literature is briefly outlined. South Crofty Mines, in order to determine the

2. In the present investigation measurements of association between vital capacity and radiological vital capacity were made on Cornish tin-miners lung changes, and to assess the value of the vital

TABLE 7

INTER-RELATION OF VITAL CAPACITY, RADIOLOGICAL CHEST VOLUME, AGE, AND $x$-RAY CATEGORY OF 105 OBSERVATIONS (GEEVOR, 1947)

\begin{tabular}{|c|c|c|c|c|}
\hline & \multicolumn{4}{|c|}{$X$-ray category } \\
\hline & I & II & III & IV \\
\hline Number of observations & 62 & 22 & 15 & 6 \\
\hline Mean age in years & $35 \cdot 13$ & $40 \cdot 23$ & $47 \cdot 93$ & $49 \cdot 5$ \\
\hline Mean radiological chest volume (R.C.V.) in sq. in. & $889 \cdot 56$ & $872 \cdot 34$ & 874.09 & $907 \cdot 73$ \\
\hline Observed mean vital capacity (V.C.) in c.cm. & $3953 \cdot 5$ & $3782 \cdot 36$ & $3417 \cdot 41$ & $2934 \cdot 5$ \\
\hline $\begin{array}{c}\text { Calculated mean V.C. from age regression equation } \\
(62 \text { normals only) } \\
. .\end{array}$ & $3953 \cdot 5$ & $3764 \cdot 27$ & $3478 \cdot 24$ & 3420.09 \\
\hline $\begin{array}{l}\text { Calculated mean V.C. from R.C.V. regression equation } \\
\text { (all } 105 \text { observations) } \\
. .\end{array}$ & $3801 \cdot 81$ & 3733.46 & $3740 \cdot 41$ & 3873.91 \\
\hline $\begin{array}{l}\text { Calculated mean V.C. from R.C.V. regression equation } \\
\text { (62 normals only) } \ldots \\
.\end{array}$ & $3953 \cdot 5$ & $3874 \cdot 36$ & $3882 \cdot 41$ & 4036.98 \\
\hline
\end{tabular}


capacity measurement as an index of a man's pulmonary condition during a survey lasting several years.

3. The initial survey in 1946 showed that at both mines the mean vital capacity of men with abnormal $x$-rays (groups II, III, and IV) was smaller than that of the normal men (group I) and at Geevor this difference was significant (variance ratio 14.63, $\mathbf{P}<0.001)$.

4. From all 262 observations combined, a significant correlation coefficient ( $r$ ) was obtained between vital capacity and age : $\mathrm{r}=0.453, \mathrm{t}=8.19$ and $\mathbf{P}<0.001$.

5. When allowance was made for age, the reduction in the mean vital capacity of abnormal men disappeared, that is, the age factor masked any influence that the lung changes, as seen radiologically, might have exerted on the vital capacity.

6. The normal men were studied in more detail and significant correlation coefficients were obtained at both mines between vital capacity and each of the variables age, height, chest expansion, and length of exposure to silica dusts. The correlation between vital capacity and the variables of stem height, weight, and exposure to metalliferous mining was significant in one or other of the mines.

7. In the 1947 follow-up survey at Geevor, the vital capacity was related to the radiological chest volume, which was found to be unaffected by age or radiological lung changes. A significant correlation coefficient between vital capacity and radiological chest volume was obtained for normal men : $r=+0.63, t=6.36, P<0.001$, and between vital capacity and age, $\mathrm{r}=-0.46, \mathrm{t}=4.04, \mathrm{P}<0.001$.

8. The decrease in the observed vital capacity with increasing severity of lung changes was again shown to be a function of age.

9. When the "expected" vital capacity was calculated from the radiological chest volume, similar and overlapping values were obtained for each of the four $x$-ray groups. Therefore a comparison of the observed and "expected" vital capacities is of no diagnostic value.

10. The limits within which a man's "expected" vital capacity would fall are so wide as to include the whole possible range of his observed volume. Therefore this comparison cannot be used to trace a man's annual progress.

11. If the standard deviation of the "expected" vital capacity is ignored in such a comparison, anomalous and misleading figures may result.

I am greatly indebted to Dr. E. A. Cheeseman for carrying out the greater part of the statistical analysis and to Dr. W. J. Martin for its completion; without their continued co-operation and assistance this study would not have been possible. My thanks are also due to Dr. J. N. Agate for assistance and to Dr. J. Gilson for much helpful advice; to Dr. K. M. A. Perry for classifying the radiographs; to Mr. H. T. Ferrier, and to Mr. J. Maclagan for taking them; to Miss A. Huntley, and to Miss E. J. Fowler for technical assistance:

\section{REFERENCES}

Aslett, E. A., Hart, P. d'Arcy, and McMichael, J. (1939). Proc. $R$. Soc. $(B), 126,502$.

Christie, R. V., and Loomis, A. L. (1933). J. Physiol., 77, 35.
Dreyer, G. (1919). Lancet, 2, 227:

Hewlett, A. W., and Jackson, N. R. (1922). Arch. intern. Med., $29,515$.

Hurtado, A., and Fray, W. W. (1933a). J. clin. Invest., 12, 807.

- , (1933b). Ibid., 12, 825 .

Kaltreider, N. L., Fray, W. W., Brooks, W. D. W., and McCann, W.S. (1935). Ibid., 14, 81 .

Hutchinson, J. (1846). Medico-chirurg. Trans., 29, 137.

Kaltreider, N. L., Fray, W. W., and Hyde, H. van Z. (1938). Amer. Rev. Tuberc., 37, 662.

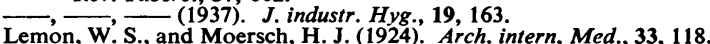

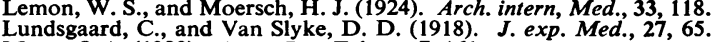
Lundsgaard, C., and Van Slyke, D. D. (1918).

Myers, J. A. (1923). Amer. Rev. Tuberc., 7,

Peabody, F. W., and Wentworth, J. A. (1917). Arch. intern. Med., $20,443$.

Schuster, E. (1911). Biometrica, 8, 40.

West, H. F. (1920). Arch. intern. Med., 25, 306. 